\title{
An automated methodology for differentiating rock from snow, clouds and sea in Antarctica from Landsat 8 imagery: a new rock outcrop map and area estimation for the entire Antarctic continent
}

\author{
Alex Burton-Johnson ${ }^{1}$, Martin Black ${ }^{1,2}$, Peter T. Fretwell ${ }^{1}$, and Joseph Kaluza-Gilbert ${ }^{3}$ \\ ${ }^{1}$ British Antarctic Survey, Cambridge, CB3 OET, UK \\ ${ }^{2}$ Department of Geography, Environment and Earth Sciences, University of Hull, Hull, HU6 7RX, UK \\ ${ }^{3}$ School of Geography, Earth and Environmental Sciences, University of Birmingham, Birmingham, B15 2TT, UK \\ Correspondence to: Alex Burton-Johnson (alerto@bas.ac.uk)
}

Received: 1 March 2016 - Published in The Cryosphere Discuss.: 7 March 2016

Revised: 27 May 2016 - Accepted: 21 June 2016 - Published: 1 August 2016

\begin{abstract}
As the accuracy and sensitivity of remote-sensing satellites improve, there is an increasing demand for more accurate and updated base datasets for surveying and monitoring. However, differentiating rock outcrop from snow and ice is a particular problem in Antarctica, where extensive cloud cover and widespread shaded regions lead to classification errors. The existing rock outcrop dataset has significant georeferencing issues as well as overestimation and generalisation of rock exposure areas. The most commonly used method for automated rock and snow differentiation, the normalised difference snow index (NDSI), has difficulty differentiating rock and snow in Antarctica due to misclassification of shaded pixels and is not able to differentiate illuminated rock from clouds. This study presents a new method for identifying rock exposures using Landsat 8 data. This is the first automated methodology for snow and rock differentiation that excludes areas of snow (both illuminated and shaded), clouds and liquid water whilst identifying both sunlit and shaded rock, achieving higher and more consistent accuracies than alternative data and methods such as the NDSI. The new methodology has been applied to the whole Antarctic continent (north of $82^{\circ} 40^{\prime} \mathrm{S}$ ) using Landsat 8 data to produce a new rock outcrop dataset for Antarctica. The new data (merged with existing data where Landsat 8 tiles are unavailable; most extensively south of $82^{\circ} 40^{\prime} \mathrm{S}$ ) reveal that exposed rock forms $0.18 \%\left(21745 \mathrm{~km}^{2}\right)$ of the total land area of Antarctica: half of previous estimates.
\end{abstract}

\section{Introduction}

Differentiating areas of snow and exposed rock in Antarctica is important in a variety of contexts, including mapping; navigation; glaciological, geological and geomorphological research; and monitoring changes in the ice sheet and its response to climate change. The only existing continentwide geospatial dataset for exposed rock in Antarctica is available from the Scientific Committee on Antarctic Research (SCAR) Antarctic Digital Database (ADD) website, http://www.add.scar.org. This dataset (the ADD rock outcrop dataset; Thomson and Cooper, 1993) has been derived through manual identification and digitisation of published topographic maps. The dataset comes from a variety of sources of varying scales and accuracies, so the accuracy of the dataset is regionally inconsistent and has no quality assessment associated with it. Although extensively used (over 2500 downloads of the rock outcrop dataset in the last 3 years; e.g. Riley et al., 2011; Golynsky et al., 2006; Vaughan et al., 1999), the data suffer from poor georeferencing, frequent misclassification of shaded snow as rock, and overestimating and generalising areas of exposed rock (Fig. 1). Additionally, as satellite-derived coastlines and digital elevation models become available, the inconsistency and inaccuracy of the present cartographically derived ADD rock outcrop dataset becomes difficult to resolve with these new data sources. There is therefore an urgent need to improve the 


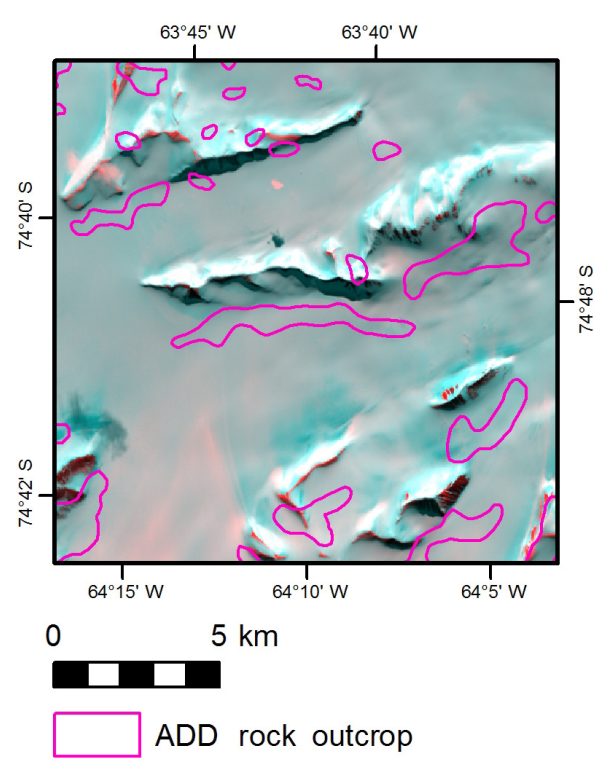

Figure 1. Example of the issues with the existing ADD rock outcrop dataset showing the problems with the georeferencing, overestimation and generalisation of areas of rock outcrop. The example uses a false-colour image using the band combination red: SWIR2; green: blue; and blue: blue. This combination accentuates rock, snow and cloud distinctions, with red/pink pixels representing rock or clouds and turquoise pixels representing snow. The Landsat 8 scene used is LC82081132013343LGN00.

consistency of georeferencing and accuracy of rock outcrop data for Antarctica.

In temperate regions methods have been formulated to automatically identify exposed rock outcrop from satellite imagery (e.g. Racoviteanu et al., 2010; Dozier, 1989; Hall et al., 1995; Paul et al., 2002, 2009; Bolch et al., 2010; Zhu and Woodcock, 2012; Zhu et al., 2015), but the methods have never been applied to Antarctica. The most commonly used existing method for delineating snow cover and rock outcrop is the normalised difference snow index (NDSI; Hall et al., 1995; Dozier, 1989). The NDSI was developed following other indices, such as the normalised difference vegetation index (NDVI; Tucker 1986, 1979), initially for application to MODIS and Landsat satellite imagery. The NDSI is calculated according to Eq. (1) (modified for Landsat 8 data) where Landsat 8 OLI (the Landsat 8 Operational Land Imager sensor) band 3 equates to spectral wavelengths of 0.53 to $0.59 \mu \mathrm{m}$ (the green band) and OLI band 6 equates to spectral wavelengths of 1.57 to $1.65 \mu \mathrm{m}$ (the short-wavelength infrared band, SWIR 1):

NDSI $=\frac{\text { OLI band } 3-\text { OLI band } 6}{\text { OLI band } 3+\text { OLI band } 6}$.

Equation (1) works on the basis that snow reflects visible wavelengths stronger than middle-infrared wavelengths whilst rock displays a slightly higher reflectance for middleinfrared wavelengths than visible wavelengths (Fig. 2) and so a threshold value can be determined for the NDSI of an image differentiating pixels of snow and rock (typically in the range 0.25 to 0.45 ; Hall et al., 1995). One problem for application of the thresholded NDSI technique to automated snow and rock differentiation is that the optimal threshold value must be determined for each individual image being analysed or even varied within the same image due to changes in illumination or fresh snow cover across the image's area (Burns and Nolin, 2014). It is often the case that the optimal threshold is manually determined on each scene by comparison to reference data; however this becomes a problem when large numbers of images need to be analysed or reference data are not available.

Although the application of the NDSI has been successful at lower latitudes (e.g. Burns and Nolin, 2014) where vertically illuminated imagery is available, high solar elevation angles in Antarctica lead to exclusion of shaded rock. This issue of shaded rock is greater in Antarctica, where unavoidably low solar elevation angles result in large percentages of the outcrop being in the shade. The problem has been addressed for glacier mapping at lower latitudes by thresholding the Landsat blue band (in addition to an NDSI or alternative band ratio threshold) due to the higher reflectance of shaded snow than shaded rock in blue wavelengths (Arendt et al., 2012; Bishop et al., 2004; Paul et al., 2007; Paul and Kääb, 2005).

Unavoidable cloud cover in some Antarctic images, especially on the Antarctic Peninsula, leads to the classification of clouds as rock exposure by the NDSI technique (Fig. 3) as the two are indiscernible using this methodology. Any effective dataset of rock outcrop in Antarctica would have to ensure that clouds are not misrepresented.

A further problem for automated rock identification at lower latitudes is debris cover on glaciers which is indiscernible in multispectral imagery from exposed rock (Paul et al., 2004). This is accentuated by the melting and ablation of low-latitude glaciers (Stokes et al., 2007) and is intensified by the large amount of debris from frost shattering and freeze-thaw activity (Fig. $4 \mathrm{a}$ and b). However, Antarctic glaciers are rarely debris-covered due the prevailing climatic conditions where constant sub-freezing conditions result in a lack of ablation (Fig. 4c and d). The limited number of positive-degree days and the lack of a day-night cycle at polar latitudes reduces freeze-thaw activity, meaning that less frost shattering takes place. Most Antarctic glaciers and ice streams are marine-terminating, and relatively few have active ablation zones (with the exception of a small percentage on the northern and eastern Antarctic Peninsula). The result is that most Antarctic glaciers are largely debris-free, removing this limitation from our study.

Here we present a new technique for automated rock outcrop identification using freely available Landsat 8 satellite data. The method is a composite technique combining separate algorithms that divide the image into cloud, liquid water, shaded snow and sunlit snow, and shaded and sunlit rock ex- 


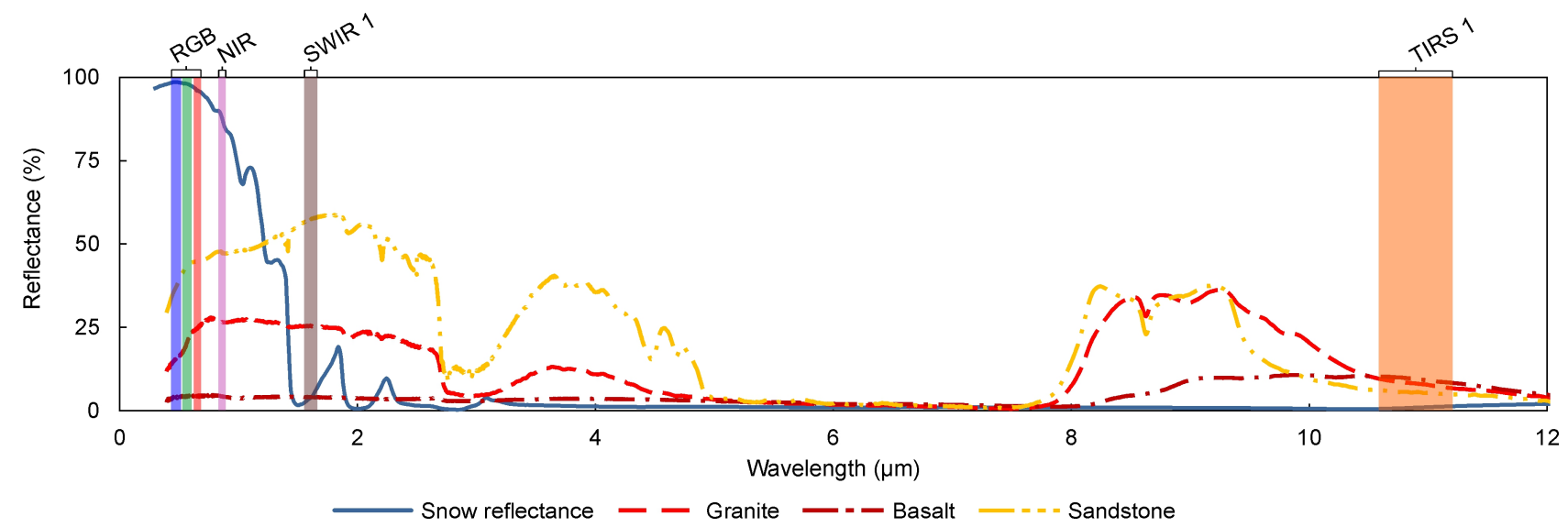

Figure 2. Spectral reflectance data for snow and rock (granite, basalt and sandstone) from the ASTER Spectral Library v1.2 (Baldridge et al., 2009). Designations of spectral regions as defined by the Landsat 8 bands: blue - band 2, 0.45-0.51 $\mu \mathrm{m}$; green - band 3, 0.53-0.59 $\mu \mathrm{m}$; red - band 4, 0.64-0.67 $\mu \mathrm{m}$; NIR, near infrared - band 5, 0.85-0.88 $\mu \mathrm{m}$; SWIR 1, shortwave infrared - band 6, 1.57-1.65 $\mu \mathrm{m}$; TIRS 1, Thermal Infrared Sensor 1 - band 10, 10.60-11.19 $\mu \mathrm{m}$.

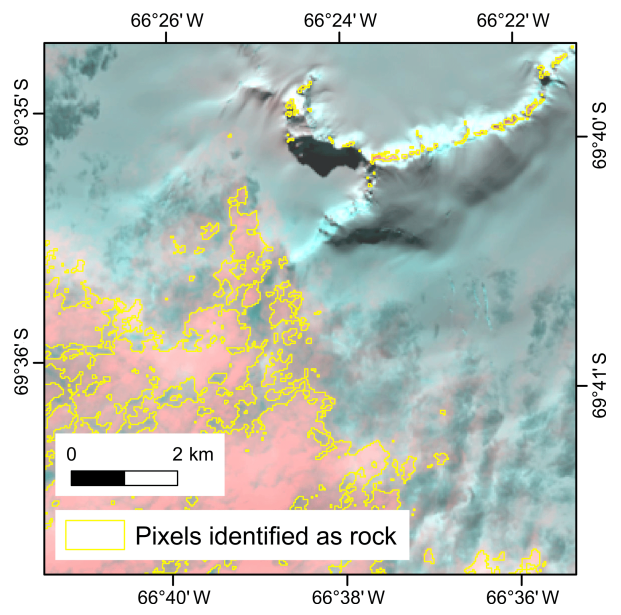

Figure 3. Illustration of the misclassification of cloud cover as rock pixels when using the NDSI technique. As in Fig. 1, the example uses a false-colour image using the band combination red: SWIR2; green: blue; and blue: blue. An NDSI threshold of 0.6 is used here to identify the rock outcrops, but at this threshold much of the cloud cover is also included. The Landsat 8 scene used is LC82161092014338LGN00.

posures. We test the method against manually digitised polygons, the existing ADD rock outcrop dataset and the NDSI to validate and compare its accuracy.

We apply the new methodology to the entire landmass of Antarctica $\left(>12000000 \mathrm{~km}^{2}\right.$ ), using Landsat 8 data over all regions of the continent that contain rock outcrop. The resulting dataset represents an improvement over the previous dataset (ADD), providing consistent and accurate estimation of the amount and location of rock outcrop in Antarctica at $30 \mathrm{~m}$ resolution.

\section{New methodology}

\subsection{Input data}

To produce a rock outcrop map for the entire Antarctic continent requires a freely available georeferenced multiband dataset. The dataset must cover high latitudes; be recently acquired; be of a high enough resolution to identify individual outcrops and geomorphological features; and be divided into sufficiently large scenes to allow for manual selection of suitable tiles for the entire continent. On this basis, the Landsat 8 multispectral satellite data were chosen for analysis. Landsat 8 is the latest and continuing satellite mission for multispectral global data acquisition launched by NASA and the United States Geological Survey (Roy et al., 2014). The satellite's Operational Land Imager (OLI) sensor records eight electromagnetic bands $(0.43-2.29 \mu \mathrm{m}$ wavelengths) at $30 \mathrm{~m}$ resolution, plus a panchromatic band $(0.50$ $0.68 \mu \mathrm{m})$ at $15 \mathrm{~m}$ resolution, whilst its Thermal Infrared Sensor (TIRS) records two thermal infrared bands (TIRS1 and TIRS2, $10.60-12.51 \mu \mathrm{m}$ ) acquired at $100 \mathrm{~m}$ resolution and resampled to $30 \mathrm{~m}$. However, the TIRS has suffered from calibration issues, and whilst calibration changes have been made to some of the TIRS1 datasets, the TIRS2 data have a larger and more variable calibration uncertainty. Consequently only TIRS1 data are used in this study.

For the production of an Antarctica-wide rock outcrop map, tiles were selected that display strong illumination and minimal cloud cover. To ensure strong illumination, we only used images taken during the day in the austral summer between September and March, with all but 17 images having solar elevation angles $>20^{\circ}$. An estimate of cloud cover is included in the metadata for Landsat 8 images, with $<30 \%$ cloud cover for all but four of the images used. Of particular importance when selecting suitable images was to ex- 

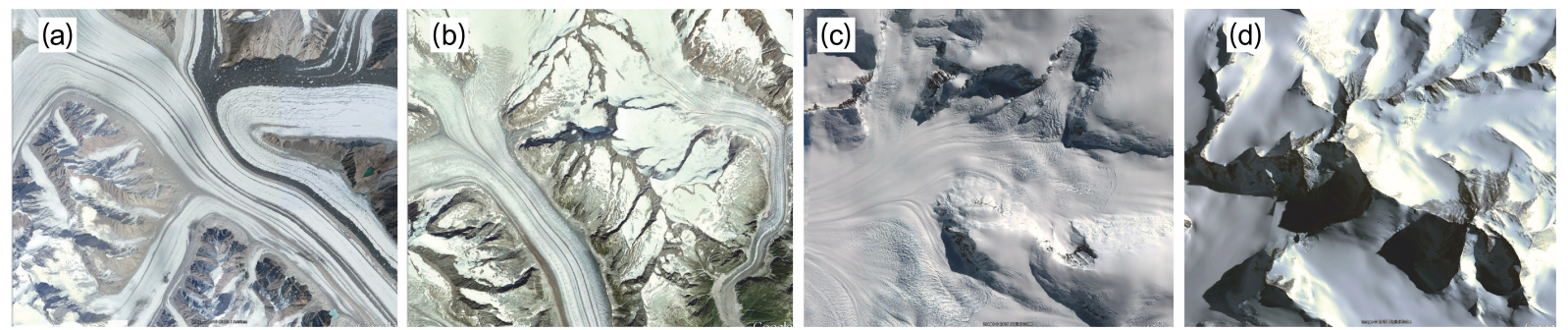

Figure 4. Comparison of debris cover for glaciers at low latitudes: (a) Karakoram Range $\left(35^{\circ} \mathrm{N}\right)$ and (b) Jungfrau Range, Alps $\left(46^{\circ} \mathrm{N}\right)$, with those of Antarctica (c), the Antarctic Peninsula $\left(66^{\circ} \mathrm{S}\right)$ and (d) Transantarctic Mountains $\left(72^{\circ} \mathrm{S}\right)$. Note the lack of surface moraine and the deep shadows in (c) and (d), typical of Antarctic glaciers where a lack of day-night cycle and year-round low temperatures restricts freeze-thaw action and the permanently low sun angles result in deep shadows in remotely sensed imagery.

clude tiles with extensive cumulus or stratocumulus cloud where shadows within and below the cloud layer can be indiscernible from illuminated rock exposure. A total of 249 Landsat 8 tiles meeting these requirements were identified using the USGS Earth Explorer website (earthexplorer.usgs. gov). The images used were acquired between October 2013 and March 2015 (details of the images used are included in the Supplement). Most areas are covered by multiple tiles, increasing the procedure's sensitivity, reducing the effect of variable snow cover and allowing outcrops to be found in areas masked by cloud in one of the composite images. Details of the tiles used are provided in the Supplement.

In addition to the raw data, pre-processed tiles $(170 \mathrm{~km}$ north-south by $183 \mathrm{~km}$ east-west) corrected for top-ofatmosphere (TOA) reflectance, surface reflectance and brightness temperature are freely available for download (espa.cr.usgs.gov). However, the calculation of surface reflectance values in Antarctica is problematic due to a lack of adequate atmospheric correction models for the continent, limited in situ atmospheric data and inadequate-quality elevation data (Black et al., 2014), rendering surface-reflectance-corrected data unsuitable. Instead, top-of-atmosphere reflectance-corrected and brightnesstemperature-converted products were used, as were also used for the Landsat Image Mosaic of Antarctica (Bindschadler et al., 2008).

\subsection{Methodology}

The new methodology identifies areas of sunlit and shaded rock through two separate workflows and then merges both outputs to produce the final dataset. Within both procedures a series of masks are produced to identify areas of exposed outcrop and to exclude areas of snow, cloud and liquid water. At each stage band ratios were used in preference to threshold values for individual bands to allow application of a single set of threshold values to a large dataset. These two procedures are detailed below, and a flowchart for executing this process is shown in Fig. 5. The complete methodology was automated within ArcPy (Zandbergen, 2013). The script is available from GitHub (github.
com/mblack2xl/AntarcticRockOutcrop). Note that raster calculations use raster values already corrected for surface reflectance and converted to brightness temperature as downloaded from the ESPA website. Raster values in these Landsat products are scaled for storage as 16 bit integers using the following scale factors: 0.0001 for TOA bands 1 to 9 , and 0.1 for bands 10 and 11 (e.g. a band 2 blue reflectance of 0.25 will be stored as 2500 , and a band 10 TIRS1 brightness temperature of $255 \mathrm{~K}$ will be stored as 2550; Anon, 2016).

Threshold values used in the methodology were determined by manually classifying 8741 pixels from three different Landsat 8 images from the Antarctic Peninsula of different latitudes, geology, illumination and cloud cover (images LC82081132013343LGN00， LC82191052013340LGN00 and LC82201072015017LGN00). Pixels were classified as representing "clouds", "sea", "sunlit rock", "shaded rock", "sunlit snow" or "shaded snow". Pixel values were extracted for the spectral bands of interest to determine the spectral properties of these six land cover classes (Fig. 6), with thresholds being set that best distinguished them.

\subsubsection{Procedure A. Sunlit rock}

\section{A.1. Sunlit rock identification: the NDSI}

Although the NDSI is unable to identify shaded rock and often misclassifies clouds as rock outcrop, it remains the best method for identifying regions of exposed sunlit rock. Consequently, it is the primary input for this methodology, with a threshold value of $<0.75$ being used to identify pixels of sunlit rock outcrop and confidently exclude pixels of snow (the upper 95th percentile of the range of values for sunlit rock, Fig. 6a).

\section{A.2. Cloud mask: TIRS1/blue and TIRS1 threshold}

One of the main problems of rock outcrop identification in Antarctica is that sunlit rock and clouds are indiscernible using the NDSI alone (Fig. 6a). Consequently we have derived a mask for sunlit snow and clouds using the thermal infrared band (Landsat 8 TIRS1, 10.60 to $11.19 \mu \mathrm{m}$, Fig. 2) and the 


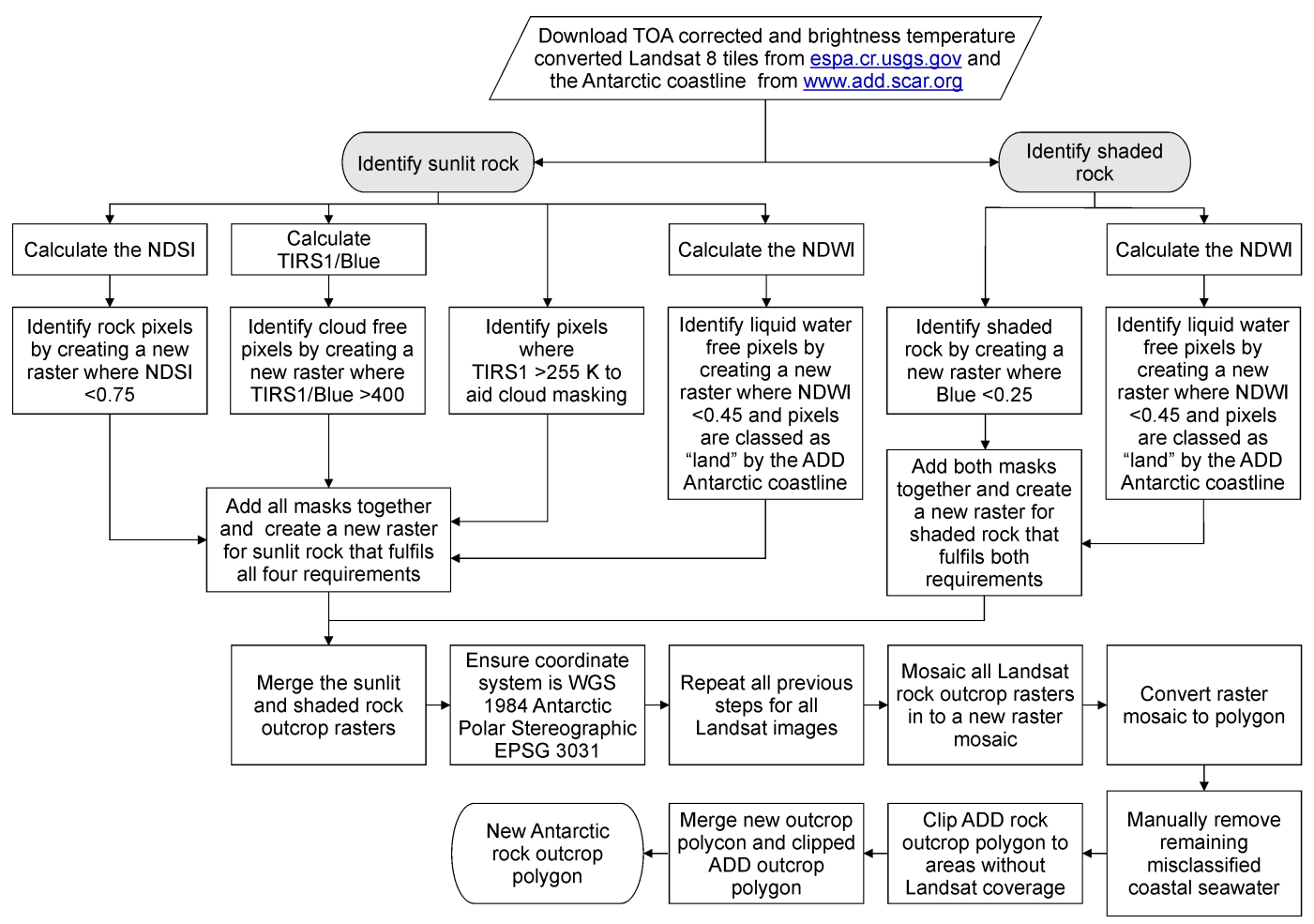

Figure 5. Flowchart for the automated identification of rock outcrops in Antarctica. Threshold values are given without the 16 bit scaling used in the corrected Landsat 8 raster images.

blue band. Using a ratio of these bands, clouds and sunlit snow give low values as they are cold but have high blue reflectance (Fig. 6b). In contrast, pixels of sunlit and shaded rock are warmer when associated with high blue reflectance (well illuminated) or colder when associated with low blue reflectance (poorly illuminated), resulting in high to moderate ratio values. However, shaded snow and liquid water also give high to moderate values. Using the scaled Landsat $8 \mathrm{im}$ ages a TIRS1/blue threshold value of $>0.4$ ( $>400$ for nonscaled TIRS1 brightness temperature and blue reflectance values) is most effective in selecting cloud-free pixels and excluding pixels of sunlit snow and cloud to produce an accurate final product, although some sunlit rock pixels are also discarded (Fig. 6b). This threshold represents the upper 95th percentile for cloud and sunlit snow pixels. To aid this cloud masking further, an absolute TIRS1 TOA brightness temperature threshold of $>255 \mathrm{~K}$ (raster values of $>2550$ in scaled brightness-temperature-converted Landsat 8 images) is also applied as $<1 \%$ of sunlit rock pixels have lower TIRS1 values whilst $10 \%$ of cloud pixels and $5 \%$ of sunlit and shaded snow pixels do have lower values (Fig. 6c).

\section{A.3. Liquid water mask: NDWI and coastline}

The most widely applied approach for the identification of liquid water in multispectral imagery is the normalised difference water index (NDWI; McFeeters, 1996). Modified for
Landsat 8 data with the Landsat 8 OLI band 3 equating to spectral wavelengths of $0.53-0.59 \mu \mathrm{m}$ (the green band) and OLI band 5 equating to spectral wavelengths of 0.85 $0.88 \mu \mathrm{m}$ (the near-infrared band, NIR), the NDWI is calculated using Eq. (2):

NDWI $=\frac{\text { OLI band } 3-\text { OLI band } 5}{\text { OLI band } 3+\text { OLI band } 5}$.

A liquid water mask is applied to both the sunlit and shaded rock identification procedures to exclude liquid water offshore (seawater) and onshore (melt ponds), and so the same threshold value of $<0.45$ is used for both (Fig. 6d). Unfortunately, due to the presence of calved ice and suspended glacial debris in Antarctic coastal seawater, a large overlap in NDWI values exists between pixels of sea and shaded rock exposure (Fig. 6d). To compromise between minimising the loss of shaded rock pixels whilst maximising seawater removal, the NDWI threshold represents the upper 90th percentile for shaded rock pixels (Fig. 6d). To aid this step, the manually derived coastline of Antarctica (available from the SCAR Antarctic Digital Database, http://www.add.scar.org) was also used as a mask for excluding seawater and sea ice. 

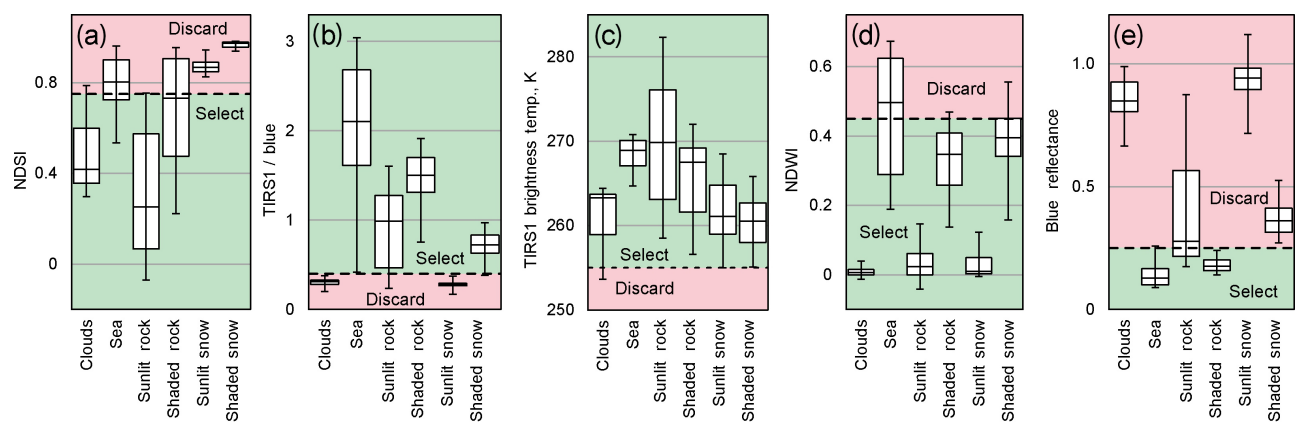

Figure 6. Box plots of extracted pixel values from three Landsat 8 tiles illustrating the different spectral properties of clouds (number of extracted pixels, $n=871)$, sea $(n=3277)$, sunlit rock $(n=1158)$, shaded rock $(n=1224)$, sunlit snow $(n=1293)$ and shaded snow $(n=918)$. TIRS1 brightness temperature, blue reflectance and the TIRS1/blue values are converted from the scaled values of the TOAcorrected and brightness-temperature-converted Landsat 8 products (Sect. 2.2). Boxes indicate the 2nd and 3rd quartiles and median values. Whiskers indicate the 5th and 95th percentile. Dashed lines indicate the chosen threshold values for the automated rock outcrop extraction and the values to be selected (green) or discarded (pink).

\subsubsection{Procedure B. Shaded rock}

\section{Shaded rock identification: blue threshold}

Even in the shade, snow is more reflective at blue wavelengths than shaded rock. By comparing the blue reflectance values of pixels representing rock and snow, a threshold reflectance value of $<0.25$ (raster values of $<2500$ in scaled TOA-corrected Landsat 8 images) was found to successfully identify pixels containing shaded rock exposure. This threshold represents the intermediate value between the upper 95th percentile for shaded rock and the lower 95th percentile for shaded snow (Fig. 6e)

\section{Liquid water mask: NDWI and coastline}

Although a blue wavelength threshold successfully differentiates shaded snow and rock, liquid water is also misclassified as rock. Thus, the NDWI and coastline mask applied to the sunlit rock data are also applied to the shaded rock data (again using the NDWI threshold value of $<0.45$, Fig. 6d). This step also aids exclusion of shaded snow pixels as $25 \%$ of their values are discarded by the NDWI threshold (Fig. 6d).

\subsubsection{Procedure C. Applying the masks and merging the datasets}

Pixels that were identified as rock by the NDSI mask and not identified as cloud or water represent sunlit rock outcrops. Similarly, pixels with blue band intensities below the threshold for shaded rock that are not subsequently identified as liquid water by the NDWI threshold represent shaded rock exposures. Merging these two outputs produced the rock outcrop map for each tile. Tiles not already projected with the WGS 1984 Stereographic South Pole spatial reference, EPSG 3031 (i.e. those at scenes with a centre latitude greater than or equal to $-63^{\circ} \mathrm{S}$, for example the South Shetland Islands) were then reprojected to this projection before the results of all the tiles were mosaicked together for the entire continent.

As most areas were covered by multiple overlapping Landsat tiles, any pixels identified as rock exposure by any of the overlying tiles were included as exposed rock in the final dataset. This was achieved by mosaicking the binary raster files produced by the workflow and taking the maximum pixel value. If a pixel was classified as snow, it was designated " 0 " by the script, or " 1 " if it represents rock. Consequently this mosaicking process stores rock outcrop pixels (" 1 ") in the raster mosaic in preference to snow ("0"). By analysing multiple overlapping tiles, the methodology becomes more sensitive to identifying rock outcrops; allows detection of rock outcrops even when they are obscured by clouds in one tile of the input data; and makes the methodology less sensitive to seasonal or short-term variation in snow cover.

Finally, the extent of the mosaicked raster dataset was converted into a new polygon shapefile and merged with the existing ADD rock outcrop dataset for areas not covered by the Landsat 8 imagery (Fig. 7).

\section{Results}

\section{Accuracy assessment}

To quantify the accuracy of the new methodology and its limitations, the extent of rock exposure was manually delineated using ten $10 \times 10 \mathrm{~km}$ images, totalling $1000 \mathrm{~km}^{2}$, or 1108890 pixels (Fig. 8, enlargements of the images in Fig. 8 can be downloaded from the Supplement). Images were selected from distal locations across the continent (Fig. 9), covering a range in geology, geomorphology and latitude. Areas of rock outcrop were manually identified by three operators. 


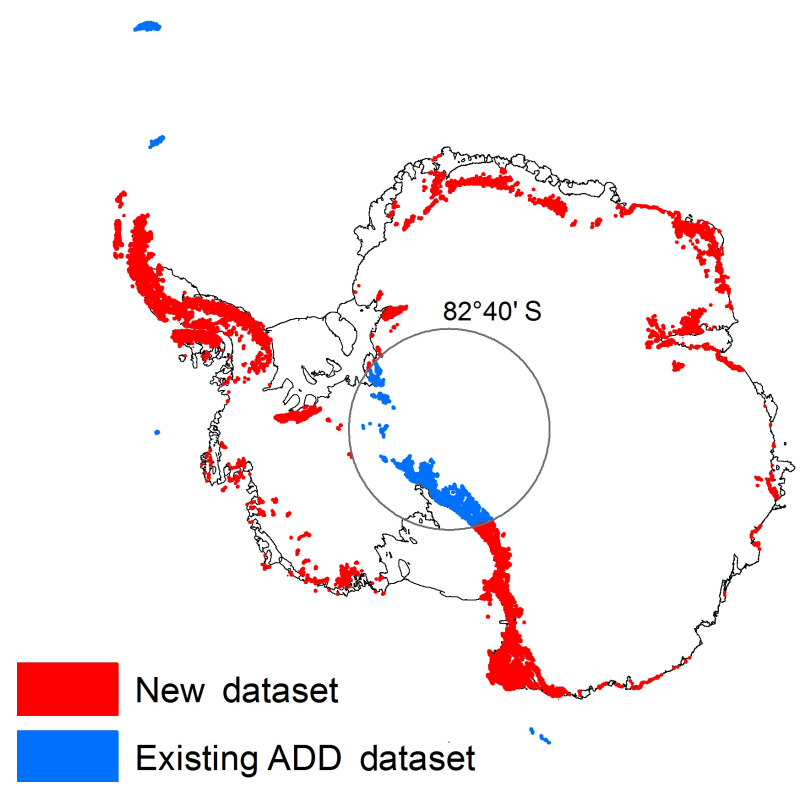

Figure 7. Rock exposure map of Antarctica showing the data sources for the new dataset. Outcrops shown in red were derived using the new remote-sensing methodology, and outcrops in blue were derived from the existing ADD rock outcrop dataset to supplement areas not covered by the Landsat 8 imagery (areas south of $82^{\circ} 40^{\prime} \mathrm{S}$ or islands lacking suitable cloud-free images). Areas of rock exposure are exaggerated for illustration.

One tile (Ryder Bay, Fig. 8g) was traced by all operators; operator variability for pixel identification (rock or non-rock) was $\pm 0.27 \%$ ( 1 standard deviation (SD)).

The manually derived land cover was compared with the existing ADD rock outcrop dataset, the new automated method and the optimum NDSI-determined output for each image. Optimum NDSI threshold values (maximum values for pixels identified as rock) were taken as those with the lowest total quantity disagreement (abundance accuracy) and allocation disagreement (location accuracy) (Pontius Jr. and Millones, 2011). As shown by Fig. 10, optimum NDSI threshold values are highly variable. For well-illuminated images without any cloud cover (Fig. 8a-e), NDSI threshold values of 0.6 or 0.7 are optimal. Images of extensive shade achieve more accurate results at higher NDSI threshold values (0.8, Fig. 8f), allowing identification of shaded rock. In contrast, images with extensive thick cloud require lower values ( 0.3 to 0.5 , Fig. $8 \mathrm{~g}$ and h) so as not to include the cloud as misidentified rock outcrop pixels. Thinner, low clouds (Fig. 8i) are not so problematic and high values (0.7) remain optimal. For mixed images (Fig. 8j) with shaded and illuminated rock with minor cloud cover, 0.7 remained the optimal threshold value.

Well-illuminated, cloud-free images produce similar classification accuracies (CA; Eq. 3) for the optimal NDSI technique and the new method (Fig. 8a-e) with low commission or omission disagreements (Fig. 11a). However, the required determination of an optimal NDSI threshold value renders this alternative methodology more involved than that used for our new dataset. In addition, even when using the optimal threshold value, the NDSI technique omits areas of rock in shaded images as well as both shaded and sunlit rock in cloudy images, leading to high and variable omission disagreements (Fig. 11b).

$$
\mathrm{CA}=\frac{\text { correctly classified pixels }}{\text { correctly classified pixels }}
$$

The ADD rock outcrop dataset produces variable accuracies. In Ryder Bay (Fig. 8g) the map has been recently been updated using manual delineation from very high resolution aerial photography and so has high accuracy with low omission and commission disagreement, similar to the new dataset. However, it is important to stress that areas of highresolution outcrop mapping are limited in the ADD rock outcrop dataset. The ADD rock outcrop dataset is more accurate than the NDSI technique in shaded images (Fig. $8 \mathrm{f}$ and j), but highly generalised and poorly georeferenced outcrop extents in other tiles (Fig. 8d, h and i) produce high and highly variable disagreements (Fig. 11), particularly in commission.

The new methodology performed poorest in images with limited areas of rock outcrop (e.g. Fig. 8h, $0.1 \%$ rock), although shade, clouds and mixed pixels of snow and rock in Fig. 8h make even manual pixel identification difficult. There are omission disagreements in shaded images (Fig. 8f and j), although these are much lower than for the alternative techniques (a mean of $15 \%$ for all images compared to $38 \%$ for the NDSI technique and $30 \%$ for the ADD rock outcrop dataset, Fig. 11b). Clouds were successfully masked and do not contribute to the commission disagreement (Fig. 8h-j).

Mean statistics for the quality assessment are recorded in Table 1 . The quality assessment shows higher accuracies for the new method (a mean of $85 \pm 8 \%, 1$-SD error of correctly identified rock pixels for all 10 images, compared with $68 \pm 30$ and $70 \pm 14 \%$ for the NDSI technique and ADD rock outcrop dataset respectively) with lower and much more consistent commission and omission disagreements than the alternative NDSI or ADD rock outcrop datasets (Fig. 11b). Classification accuracies (Eq. 3) are $74 \pm 9 \%$ 1SD error for the new method compared to $63 \pm 27 \%$ for the optimal NDSI method or $39 \pm 19 \%$ for the existing ADD rock outcrop dataset (Fig. 11a).

\section{Discussion}

This is the first automated methodology for the differentiation of snow and rock in Antarctica, from which a new outcrop map of the entire Antarctic continent has been produced at higher and more consistent accuracies than existing data and techniques (Fig. 11). The new dataset is available online via the SCAR Antarctic Digital Database (http: //www.add.scar.org) and from this article's Supplement. 

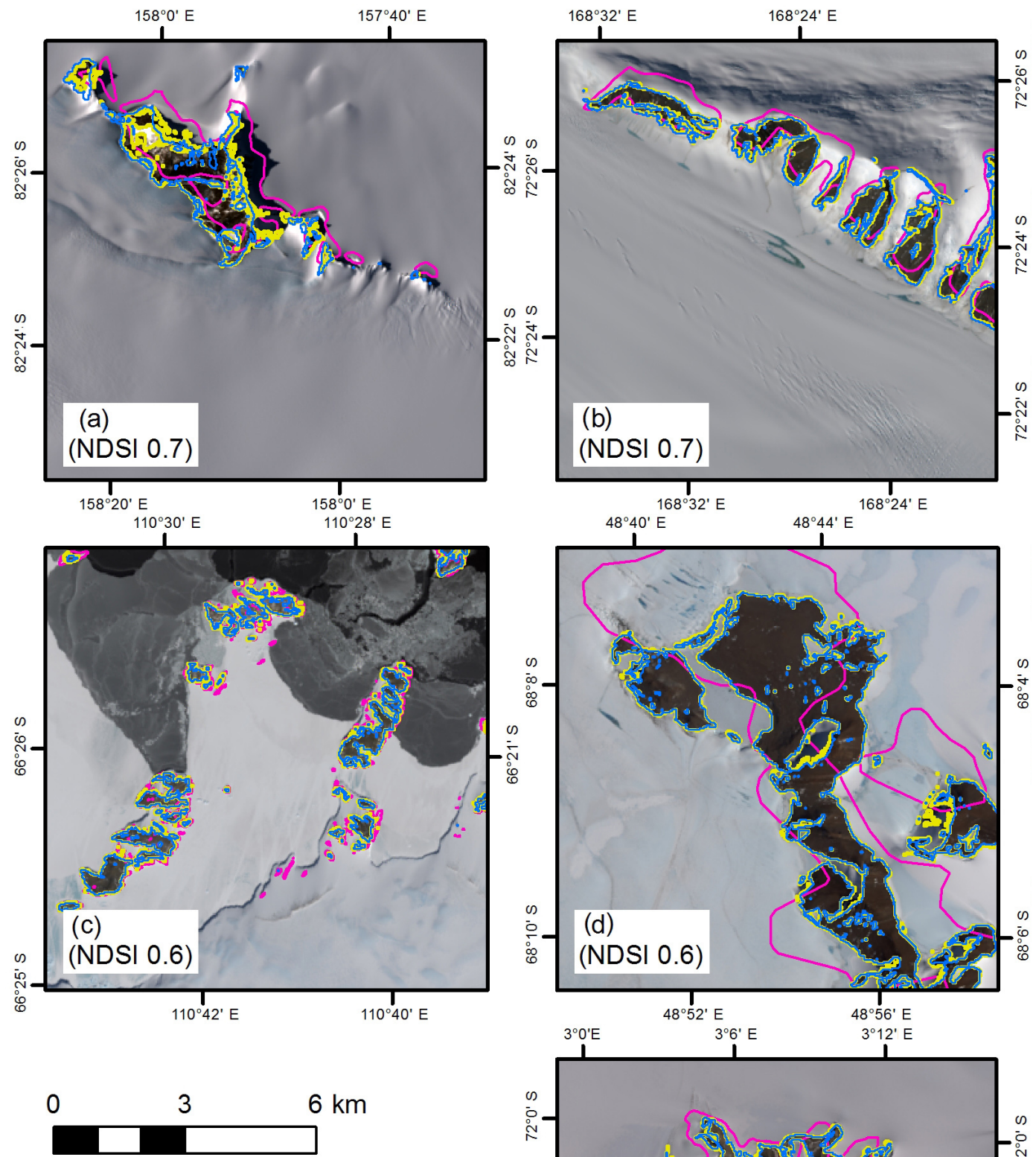

Optimum NDSI

Automated outcrop identification (presented here)

ADD rock outcrop

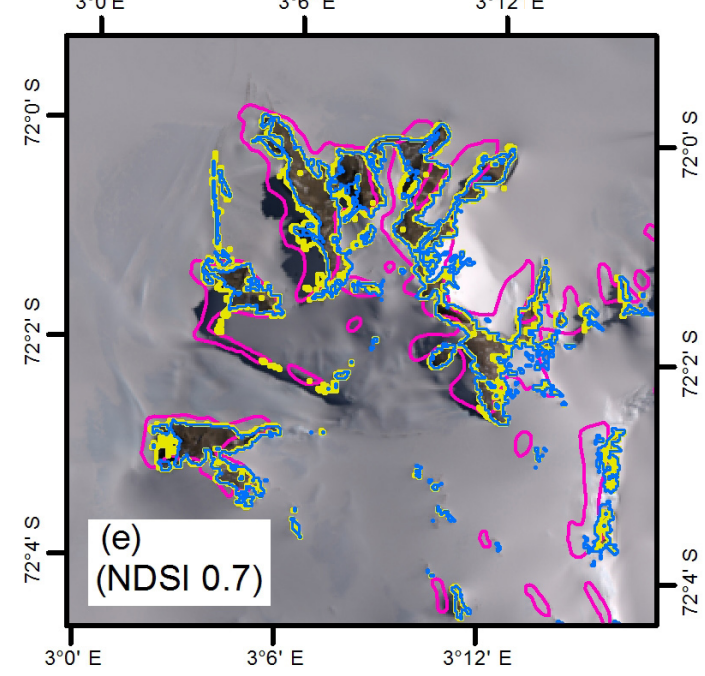

Figure 8. 

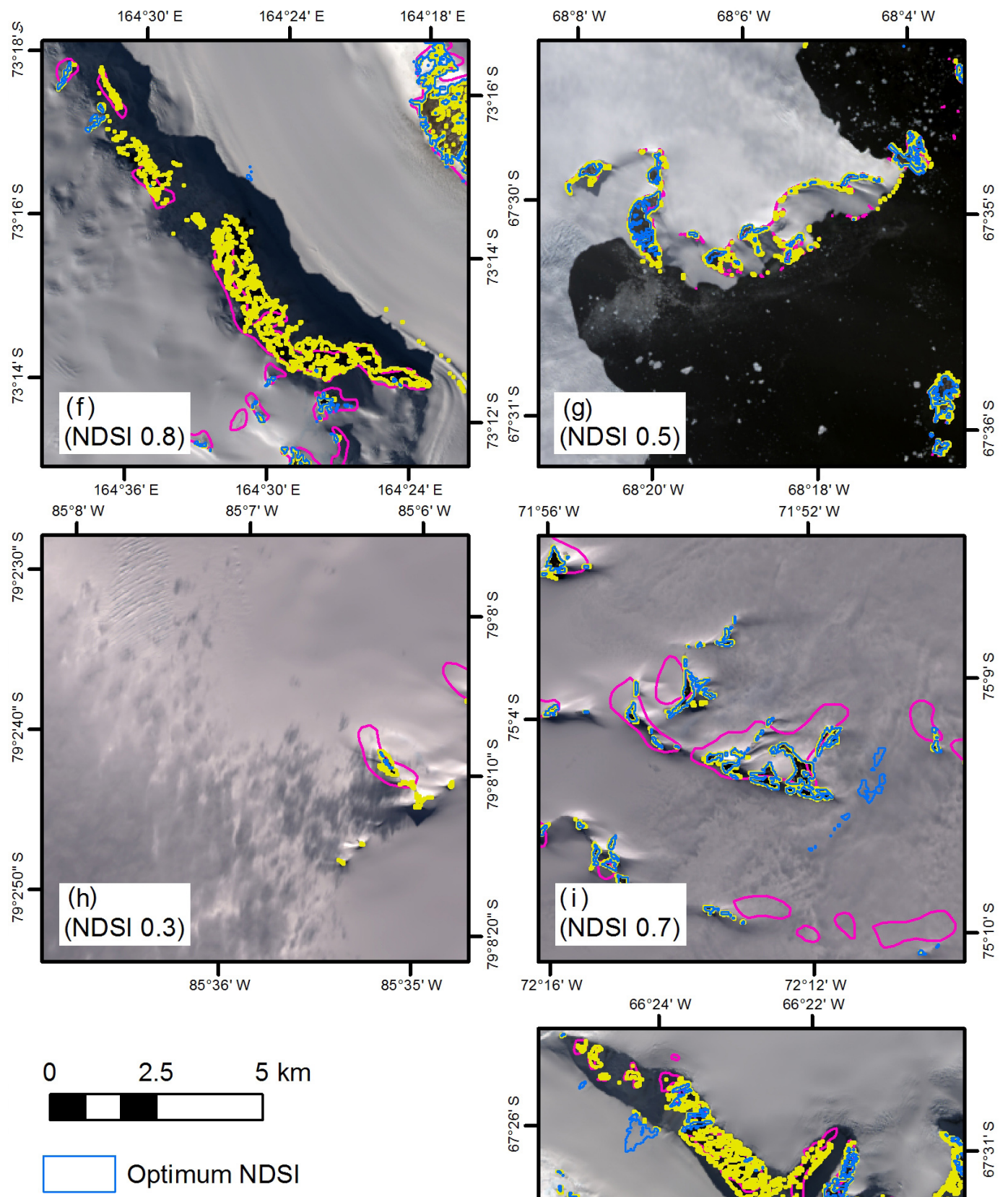

Automated outcrop identification (presented here)

ADD rock outcrop

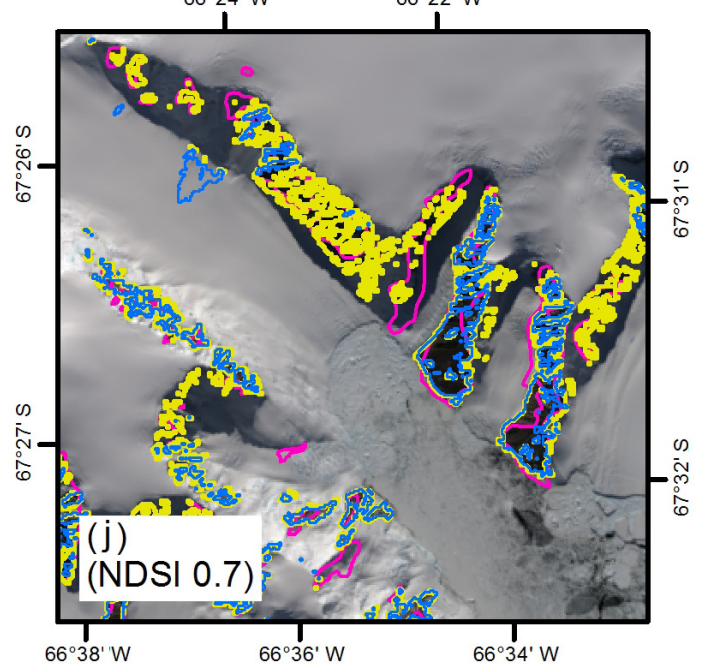

Figure 8. Images used for the quality assessment overlain by the three alternative methodologies and datasets: pixels extracted using optimum NDSI thresholds for each image (NDSI threshold values shown in brackets); pixels extracted using the new methodology presented here; and the extents of the current ADD rock outcrop map. Enlargements of these images can be downloaded from the Supplement. Scene locations are indicated in Fig. 9. 
Table 1. Summary of mean accuracy assessment vales for the 10 images evaluated.

\begin{tabular}{lrrrrrrrr}
\hline Methodology & Correct \% & SD & Commission \% & SD & Omission \% & SD & $\begin{array}{r}\text { Classification } \\
\text { accuracy } \%\end{array}$ & SD \\
\hline This study & 85 & 8 & 17 & 13 & 15 & 8 & 74 & 9 \\
Optimum NDSI & 68 & 30 & 7 & 6 & 32 & 30 & 63 & 27 \\
ADD rock outcrop & 70 & 14 & 154 & 212 & 30 & 14 & 39 & 19 \\
\hline
\end{tabular}

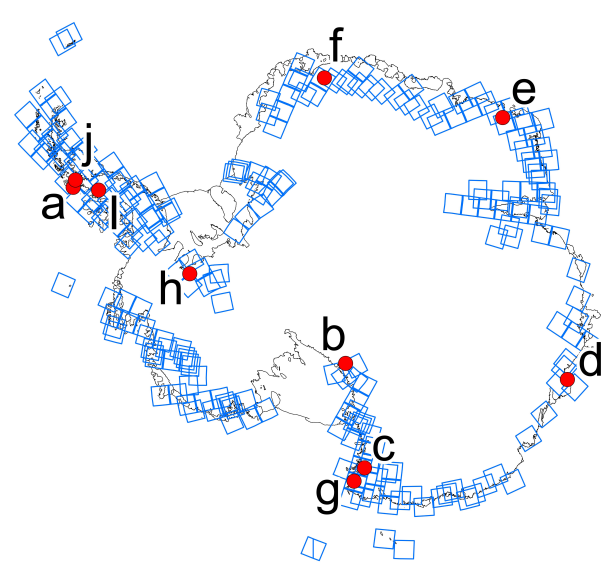

Figure 9. Locations of the 249 Landsat 8 tiles (blue squares) used to identify rock outcrop in Antarctica and the locations $(\mathbf{a}-\mathbf{j})$ of the $10 \times 10 \mathrm{~km}$ images used for the quality assessment in Fig. 8 .

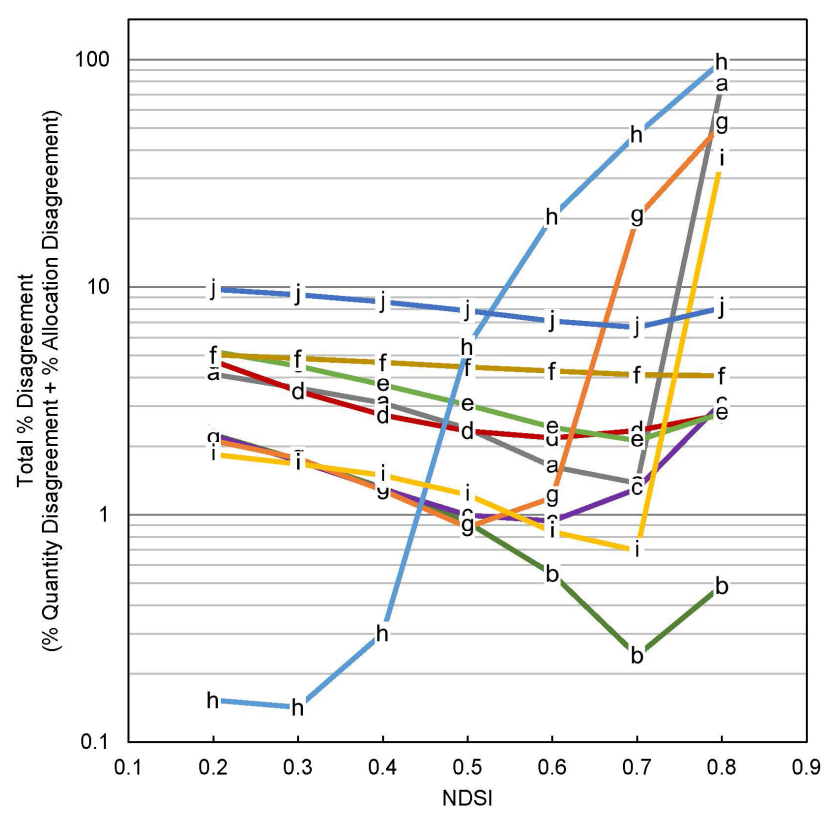

Figure 10. Total quantity and allocation disagreement values (Pontius Jr. and Millones, 2011) for pixels extracted from the images in Fig. 8 using the NDSI threshold technique.

Despite the poorer accuracy of the ADD rock outcrop dataset (39\% classification accuracy compared to $74 \%$ for the new methodology, Fig. 11a), due to the methodology by which it was derived, certain features are better represented. This includes South Georgia and the South Orkney Islands, where a lack of cloud-free imagery in the late austral summer (when the outcrops are not covered by snow) prevents automated outcrop identification. Consequently, rock outcrop extents in these areas are derived from the existing ADD dataset rather than remote-sensing imagery, in addition to outcrops south of $82^{\circ} 40^{\prime} \mathrm{S}$ (Fig. 7).

It is important when using the new Landsat 8 rock outcrop map to consider seasonal variability in snow cover and that most outcrops were derived from multiple tiles from different years and different months of the austral summer. As a result the map may not be representative of current conditions and may not consistently represent maximum outcrop extent across the continent.

\subsection{Limitations}

Using the new methodology, we have produced a revised map of rock outcrops in Antarctica. Landsat 8 does not provide coverage south of $82^{\circ} 40^{\prime} \mathrm{S}$, so the existing ADD rock outcrop dataset was clipped to latitudes greater than this and merged with the new automatically derived data to produce the final dataset. There are two further limitations to the new methodology:

1. Because an overlap exists between the NDWI values of shaded rock and liquid water (Fig. 6d) and because of inaccuracies in the existing coastal vector dataset, some pixels of coastal seawater not masked by the ADD coastline have been misidentified as exposed rock in all coastal scenes containing seawater pixels. This is particularly problematic for pixels adjacent to seawater rich in calved ice and glacial debris (Fig. 12a). These pixels are spectrally identical to shaded rock and thus cannot be excluded automatically from the data. Consequently these pixels were manually removed from the final dataset, with the distinction of shaded rock and liquid water being made by eye. It should be noted that some of these misidentified pixels may still be present. However, as no manual editing was done on land, the repeatability of this methodology should not be affected.

2. Even though spectral properties have been chosen that distinguish rock pixels from those of snow, clouds or 
(a)

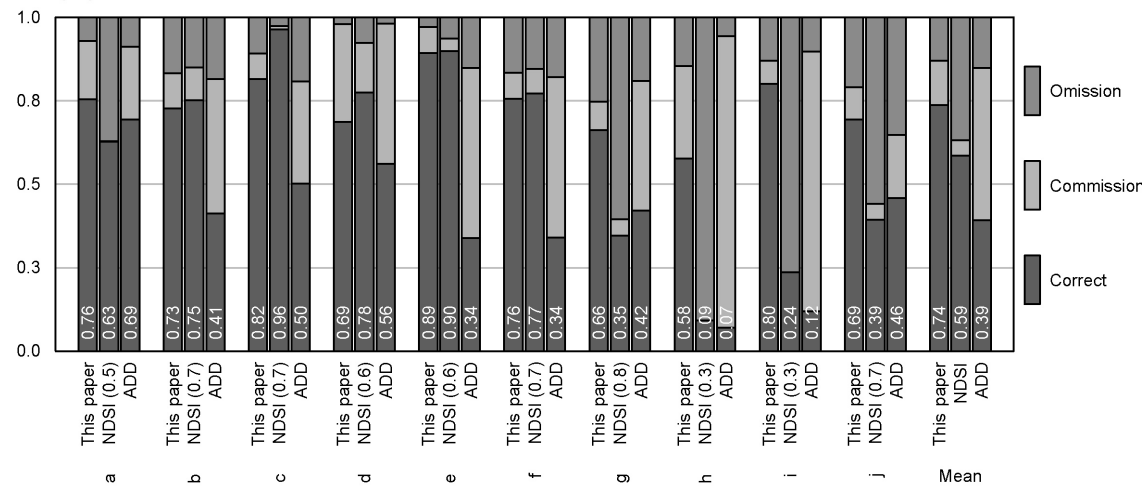

(b)

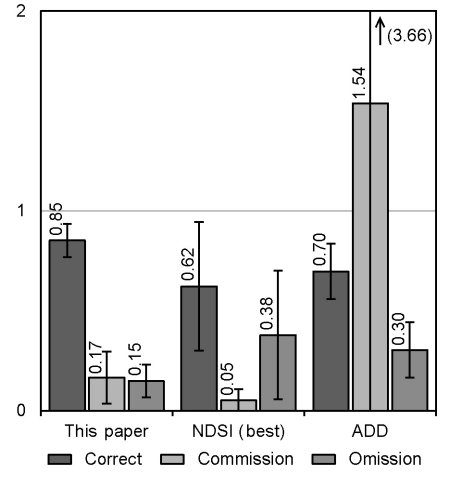

Figure 11. (a) Accuracy assessment data normalised to 1 for correctly classified pixels and pixels of omission and commission disagreements for the images in Fig. 8. Optimal NDSI values used are shown in brackets. Values in columns are the classification accuracy values (Eq. 3). (b) Average accuracy assessment values for the three alternative datasets showing the mean values for pixels of correct classification, commission disagreement and omission disagreement for the 10 quality control images (Fig. 8) with error bars at 1 SD.
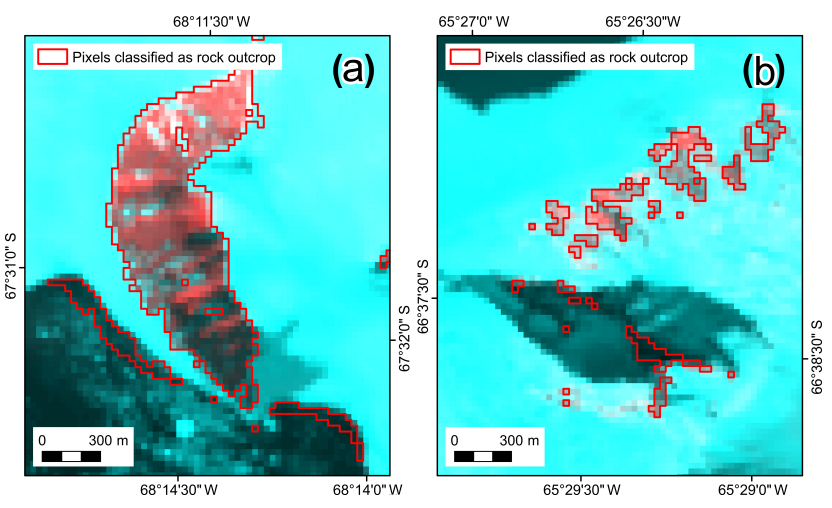

Figure 12. Examples of the new methodology's limitations, comparing the new dataset with false-colour Landsat 8 images. The band combination (red: SWIR2; green: blue; blue: blue) is chosen to accentuate rock, snow and seawater distinctions, with red pixels representing rock, turquoise pixels for snow and dark green to black pixels for seawater. (a) An example of seawater near calving ice classified as rock (later removed manually). (b) An illustration of conservative outcrop extent estimation using the new technique. This is a result of the mildly conservative threshold values that had to be chosen to allow the automated analysis of so many tiles over the area of an entire continent.

sea, some overlap exists where pixels remain ambiguous (Fig. 6). Consequently, to allow automated analysis over such a large area, mildly conservative threshold values were chosen. For example, the NDSI threshold for sunlit rock was set at the 95th percentile rather than the complete range exhibited by sunlit outcrops as this excludes any overlap with the range of NDSI values for sunlit snow (Fig. 6a). This results in the exclusion of some pixels of exposed rock that are spectrally similar to clouds and snow (e.g. Fig. 12b).
3. Due to the $100 \mathrm{~m}$ spatial resolution of the TIRS band, small outcrops around the continent (especially those less than $60 \mathrm{~m}$ or 2 pixels across) are often excluded by the new technique and may be better represented in the ADD rock outcrop dataset.

4. Whilst Antarctic glaciers rarely show any debris cover (Fig. 4), there are local occurrences where extensive debris cover does occur (most notably in the vicinity of the Dry Valleys and the NW coast of the Ross Ice Shelf) which are mapped as outcrop in the new dataset. However, it should be noted that these occurrences are isolated on the continental scale. As this project aims to provide a consistent and automated approach that can be reproduced in the future (for example to monitor change in ice cover over time or season), our methodology attempts to be as free as possible from manual changes. We accept that in some areas localised occurrences of debris-covered glaciers may need to be manually altered if detailed topographic maps of rock outcrop are required.

\subsection{Total outcrop area}

We calculate (using the South Pole Lambert azimuthal equalarea projection) that the existing ADD rock outcrop dataset has a $44900 \mathrm{~km}^{2}$ area of rock outcrop, equivalent to $0.37 \%$ of the total land area of Antarctica $\left(12188650 \mathrm{~km}^{2}\right.$; the SCAR Antarctic Digital Database, http://www.add.scar.org). In contrast the new data have a $21745 \mathrm{~km}^{2}$ total area of rock outcrop ( $\pm 5654 \mathrm{~km}^{2}$ based on the $74 \%$ calculated classification accuracy, Sect. 3.1), equivalent to $0.18 \pm 0.05 \%$ of the continent's land area and $48 \%$ of the previous estimate. This is a significant decrease and highlights an overestimation in the current predictions of rock outcrop extent in Antarctica. 


\subsection{Applications and future developments}

The new Landsat 8 rock outcrop map will provide a revised and accurate base dataset for future topographical, glaciological, geological and geomorphological mapping. A number of satellite programmes collecting new high-resolution colour images have recently been launched or are planned for launch in the near future, including the DigitalGlobe WorldView-3 satellite (launched 2014), NASA's HyspIRI satellite (proposed but not yet under development), European Space Agency's Sentinel program (three satellites already launched with more under development) and the continuing Landsat data acquisition (continuing acquisition from Landsat 7 and 8, with Landsat 9 planned for launch in 2023). These new datasets will allow further application of this technique at higher resolutions and consequently higher accuracies, allowing future improvement of the datasets' broader applications. Application of the new technique to these alternative datasets would however require modification of the threshold values for each mask in the procedure.

Once the available imagery has improved, the Antarctic rock outcrop dataset will again be updated to exploit the new data and increase coverage of the continent (especially south of $82^{\circ} 40^{\prime} \mathrm{S}$ ). By providing the code used in this study (available from GitHub, github.com/mblack2xl/ AntarcticRockOutcrop), users will be able to apply the new methodology to their specific areas of interest and modify the thresholds for improved results on local scales. Such work may be possible to integrate into future iterations of the continental dataset if users inform the authors regarding their new datasets.

\section{Conclusions}

A new map of exposed rock outcrop has been developed for the Antarctic continent. The new map was achieved via an automated methodology employing Landsat 8 multispectral imagery. The new methodology uses the NDSI technique to identify sunlit rock exposure and low blue intensities for shaded rock, and then applies separate masks to remove incorrectly classified pixels of cloud, snow and liquid water. This is the first automated methodology for rock outcrop identification in Antarctica and achieves higher and more consistent accuracies than the existing dataset or what can be achieved using the alternative automated technique (the NDSI). Assessing the accuracy of these alternative techniques and datasets across a range of images gives a mean value for correct pixel identification of $85 \pm 8 \%$ for the new method compared to $70 \pm 14 \%$ using the existing ADD rock outcrop dataset or $68 \pm 30 \%$ for the NDSI technique using optimal values. Overall classification accuracies accounting for omission and commission errors improve from $39 \%$ for the existing ADD rock outcrop dataset and $63 \%$ for outcrop detection using optimal NDSI thresholds to $74 \%$ using the new technique.

The new map, supplemented by existing data for latitudes south of $82^{\circ} 40^{\prime} \mathrm{S}$ (the limit of Landsat 8 coverage), reveals that rock outcrop forms $0.18 \pm 0.05 \%\left(21745 \mathrm{~km}^{2}\right)$ of the total land area of Antarctica, $48 \%$ of the previous estimate $\left(0.37 \%, 44900 \mathrm{~km}^{2}\right)$.

\section{Data availability}

The new Landsat 8 derived rock outcrop dataset is available in the Supplement to this article; from the SCAR Antarctic Digital Database, http://www.add.scar.org; and from the following doi:10.5285/f7947381-6fd7-466f-8894$25 \mathrm{~d} 3262$ cbcf5.

\section{The Supplement related to this article is available online at doi:10.5194/tc-10-1665-2016-supplement.}

Acknowledgements. We would like to thank Allen Pope and our anonymous second reviewer for their positive, helpful and thorough reviews. This study is part of the British Antarctic Survey Polar Science for Planet Earth programme, funded by the Natural Environment Research Council (NERC). Martin Black was funded by a NERC research studentship (NE/K50094X/1).

Edited by: K. Matsuoka

Reviewed by: A. Pope and one anonymous referee

\section{References}

Anon: Product Guide, Provisional Landsat 8 Surface Reflectance Product, Department of the Interior, US Geological Survey, USA, available from: http://landsat.usgs.gov/documents/ provisional_18sr_product_guide.pdf, 2016.

Arendt, A., Bolch, T., Cogley, J. G., Gardner, A., Hagen, J.-O., Hock, R., Kaser, G., Pfeffer, W. T., Moholdt, G., Paul, F., et al.: Randolph glacier inventory [v2.0]: A dataset of global glacier outlines, global land ice measurements from space, Boulder, Colorado, USA, available at: http://www.glims.org/RGI/RGI_Tech_ Report_V2.0.pdf, 2012.

Baldridge, A. M., Hook, S. J., Grove, C. I., and Rivera, G.: The ASTER spectral library version 2.0, Remote Sens. Environ., 113, 711-715, 2009.

Bindschadler, R., Vornberger, P., Fleming, A., Fox, A., Mullins, J., Binnie, D., Paulsen, S. J., Granneman, B., and Gorodetzky, D.: The Landsat image mosaic of Antarctica, Remote Sens. Environ., 112, 4214-4226, 2008.

Bishop, M. P., Olsenholler, J. A., Shroder, J. F., Barry, R. G., Raup, B. H., Bush, A. B., Copland, L., Dwyer, J. L., Fountain, A. G., Haeberli, W., et al.: Global Land Ice Measurements from Space (GLIMS): remote sensing and GIS investigations of the Earth's cryosphere, Geocarto Int., 19, 57-84, 2004. 
Black, M., Fleming, A., Riley, T., Ferrier, G., Fretwell, P., McFee, J., Achal, S., and Diaz, A. U.: On the Atmospheric Correction of Antarctic Airborne Hyperspectral Data, Remote Sens., 6, 44984514, 2014.

Bolch, T., Menounos, B., and Wheate, R.: Landsat-based inventory of glaciers in western Canada, 1985-2005, Remote Sens. Environ., 114, 127-137, 2010.

Burns, P. and Nolin, A.: Using atmospherically-corrected Landsat imagery to measure glacier area change in the Cordillera Blanca, Peru from 1987 to 2010, Remote Sens. Environ., 140, 165-178, 2014.

Dozier, J.: Spectral signature of alpine snow cover from the Landsat Thematic Mapper, Remote Sens. Environ., 28, 9-22, 1989.

Golynsky, A., Chiappini, M., Damaske, D., Ferraccioli, F., Finn, C. A., Ishihara, T., Kim, H. R., Kovacs, L., Masolov, V. N., Morris, P., et al.: ADMAP - a digital magnetic anomaly map of the Antarctic, in Antarctica, Springer, 109-116, doi:10.1007/3-54032934-X_12, 2006.

Hall, D. K., Riggs, G. A., and Salomonson, V. V.: Development of methods for mapping global snow cover using moderate resolution imaging spectroradiometer data, Remote Sens. Environ., 54, 127-140, 1995 .

McFeeters, S. K.: The use of the Normalized Difference Water Index (NDWI) in the delineation of open water features, Int. J. Remote Sens., 17, 1425-1432, 1996.

Paul, F. and Kääb, A.: Perspectives on the production of a glacier inventory from multispectral satellite data in Arctic Canada: Cumberland Peninsula, Baffin Island, Ann. Glaciol., 42, 59-66, 2005.

Paul, F., Kääb, A., Maisch, M., Kellenberger, T., and Haeberli, W.: The new remote-sensing-derived Swiss glacier inventory: I. Methods, Ann. Glaciol., 34, 355-361, 2002.

Paul, F., Huggel, C., and Kääb, A.: Combining satellite multispectral image data and a digital elevation model for mapping debriscovered glaciers, Remote Sens. Environ., 89, 510-518, 2004.

Paul, F., Kääb, A., and Haeberli, W.: Recent glacier changes in the Alps observed by satellite: Consequences for future monitoring strategies, Glob. Planet. Change, 56, 111-122, 2007.

Paul, F., Barry, R. G., Cogley, J. G., Frey, H., Haeberli, W., Ohmura, A., Ommanney, C. S. L., Raup, B., Rivera, A., and Zemp, M.: Recommendations for the compilation of glacier inventory data from digital sources, Ann. Glaciol., 50, 119-126, 2009.
Pontius Jr., R. G. and Millones, M.: Death to Kappa: birth of quantity disagreement and allocation disagreement for accuracy assessment, Int. J. Remote Sens., 32, 4407-4429, 2011.

Racoviteanu, A. E., Paul, F., Raup, B., Khalsa, S. J. S., and Armstrong, R.: Challenges and recommendations in mapping of glacier parameters from space: results of the 2008 Global Land Ice Measurements from Space (GLIMS) workshop, Boulder, Colorado, USA, Ann. Glaciol., 50, 53-69, 2010.

Riley, T. R., Flowerdew, M. J., and Haselwimmer, C. E.: Geological Map of Eastern Graham Land, Antarctic Peninsula (1 : 625000 scale), British Antarctic Survey, Cambridge, UK, 2011.

Roy, D. P., Wulder, M. A., Loveland, T. R., Woodcock, C. E., Allen, R. G., Anderson, M. C., Helder, D., Irons, J. R., Johnson, D. M., Kennedy, R., and others: Landsat- 8 : Science and product vision for terrestrial global change research, Remote Sens. Environ., 145, 154-172, 2014.

Stokes, C. R., Popovnin, V., Aleynikov, A., Gurney, S. D., and Shahgedanova, M.: Recent glacier retreat in the Caucasus Mountains, Russia, and associated increase in supraglacial debris cover and supra-/proglacial lake development, Ann. Glaciol., 46, 195203, 2007.

Thomson, J. W. and Cooper, A. P. R.: The SCAR Antarctic digital topographic database, Antarct. Sci., 5, 239-244, 1993.

Tucker, C. J.: Red and photographic infrared linear combinations for monitoring vegetation, Remote Sens. Environ., 8, 127-150, 1979.

Tucker, C. J.: Cover Maximum normalized difference vegetation index images for sub-Saharan Africa for 1983-1985, Int. J. Remote Sens., 7, 1383-1384, 1986.

Vaughan, D. G., Bamber, J. L., Giovinetto, M., Russell, J., and Cooper, A. P. R.: Reassessment of net surface mass balance in Antarctica, J. Climate, 12, 933-946, 1999.

Zandbergen, P. A.: Python scripting for ArcGIS, ESRI Press, 353 pp., 2013.

Zhu, Z. and Woodcock, C. E.: Object-based cloud and cloud shadow detection in Landsat imagery, Remote Sens. Environ., 118, 8394, 2012.

Zhu, Z., Wang, S., and Woodcock, C. E.: Improvement and expansion of the Fmask algorithm: cloud, cloud shadow, and snow detection for Landsats 4-7, 8, and Sentinel 2 images, Remote Sens. Environ., 159, 269-277, 2015. 